\title{
Economic Evaluation of the Prospects for Bioenergy Development of Ukraine in Conditions of Globalization
}

\author{
Svitlana Matsyura* \\ Department of Economics and \\ entrepreneurship \\ Kryvyi Rih Economic Institute SHEI \\ "Kyiv National Economics University \\ named after Vadym Hetman" \\ Kryvyi Rih, Ukraine \\ mazura_si@kneu.dp.ua
}

\author{
Viktoriia Radko \\ Department of Economics and \\ entrepreneurship \\ Kryvyi Rih Economic Institute SHEI \\ "Kyiv National Economics University \\ named after Vadym Hetman" \\ Kryvyi Rih, Ukraine \\ radko_vm@kneu.dp.ua
}

\author{
Zhanna Breher \\ Department of Economics and \\ entrepreneurship \\ Kryvyi Rih Economic Institute SHEI \\ "Kyiv National Economics University \\ named after Vadym Hetman" \\ Kryvyi Rih, Ukraine \\ breger.ja@gmail.com
}

\begin{abstract}
Topicality. Globalization is characterized by exponential rates of production of goods and services, extraction of natural resources, increase in energy consumption. This has led to climate change. As a result, it is necessary to find a solution to this problem in order to reduce the negative impact of humanity on the environment. One such solution is the production of bioenergy.
\end{abstract}

Ukraine is still an agro-industrial country, and it has a high bioenergy potential. In recent years (2013-2018) bioenergy of Ukraine has started to develop, but the existing pace of development is not enough to achieve the goals set out in the main plan of the article.

Potential bioenergy producers claim that there is no economic benefit from such activities. Therefore, this statement is analyzed and refuted. The paper evaluates the bioenergy potential of Ukraine, proves the economic effect of bioenergy production, forecasts the development of this sector, analyzes the impact of subsidizing natural gas consumers on the development of the bioenergy sector.

The paper assessed the bioenergy potential of Ukraine in comparison with other countries, took into account the participation of Ukraine in international programs, forecast the development of the domestic bioenergy market. The study revealed that activities in the field of bioenergy has an economic and investment effect.

Keywords-bioenergy, economic evaluation, subsidizing, «green» tariffs, biowaste.

\section{INTRODUCTION}

Globalization is characterized by an exponential rate of production of goods and services, extraction of natural resources, and an increase in energy consumption. This has caused climate change.

Nevertheless, despite the fact that globalization leads to air pollution, water resources, climate change; it is the most effective mechanism to combat the negative consequences. As a result of the transition of countries ' activities to the level of the global economy, the interaction between economic entities, the implementation of mechanisms of influence on socio-economic and political problems is simplified.
Despite the introduction of Ukraine to the technological, information trends, our country remains agricultural with rich soils and water resources. The activity of the agricultural sector is accompanied by significant biowaste, which can be converted into bioenergy. Only in Ukraine, the reduction of natural gas emissions due to its replacement with biomass according to the forecast for 2019 and 2020 will have a high result. The problem of air pollution in the short and long term (2100) considered in work of William Nordhaus "Warming the world: economic models of global warming" [17], who in October 2018 received the Nobel prize for research on the impact of climate change on the economy.

Thus, the domestic bioenergy sector requires additional financing, which can be provided by foreign investment and international cooperation. Such opportunities are opened up by globalization, which simplifies relations between countries, companies and banking institutions.

Purpose of article. Study of the dynamics of bioenergy development, its potential, determining the investment attractiveness of this sector of the economy by determining the economic benefits of investment, evaluation of the economic potential of the investment project. In addition, the task of the work is to compare the bioenergy sector in Europe and Asia, to analyze their policies for the development of bioenergy. Identification of problems of bioenergy development and doubtful investment attractiveness (if found), development of recommendations to accelerate the development of the domestic bioenergy sector.

Aim of article and tasks. Research of the dynamics of bioenergy development, its potential, determining the investment attractiveness of this sector of the economy by determining the economic benefits of investment, evaluation of the economic potential of the investment project. In addition, the task of the work is to compare the bioenergy sector in Europe and Asia, to analyze their policies for the development of bioenergy. Identification of problems of bioenergy development and doubtful investment attractiveness (if found), development of recommendations to accelerate the development of the domestic bioenergy sector. 
Problem statement. Ukraine is still an agro-industrial country, which means that it has a high bioenergy potential. In recent years (2013-2018), bioenergy in Ukraine began to develop, but the current pace of development is not enough to achieve the goals, which are mainly presented in the article.

Scientific novelty. The novelty of the work lies in the economic rationale for the development of bioenergy to reduce the amount of subsidies to consumers of natural gas and compliance with the mechanism of "green tariffs". In addition, the paper shows the economic effect of bioenergy production.

Research methods: quantitative and qualitative data analysis, comparison and measurement, methods of deduction and induction, modelling and forecasting, analysis and synthesis, visual-graphical methods, a combined method of similarity and difference, abstraction.

The General problem of ecology and energy is considered in the works of W. D. Nordhaus, and J. E. Boyer [17], João Roberto Menucelli [8], Geraldo Jose Ferraresi de Araujo [2], Song-Fang Han [10].

The question of development of domestic bio-energy researchers are doing, such as $\mathrm{H}$. Heletukha T. Zheleznaya [3]. Therefore, as this issue requires resolution and the legal research in this area do S. A. Svirkov, A. P. Vershynin, and S. D. Bilots'kyy [9]. However, this area is still unexplored.

\section{RESEARCH RESULTS}

The bioenergy potential of Ukraine is high, as evidenced by the data shown in Figures 1, 2 and 3.

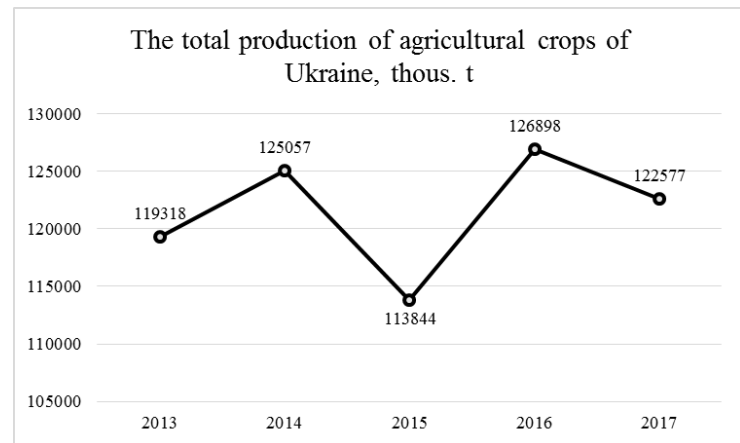

Fig. 1. Total production of agricultural crops, thousand tons (developed by the authors using [15])

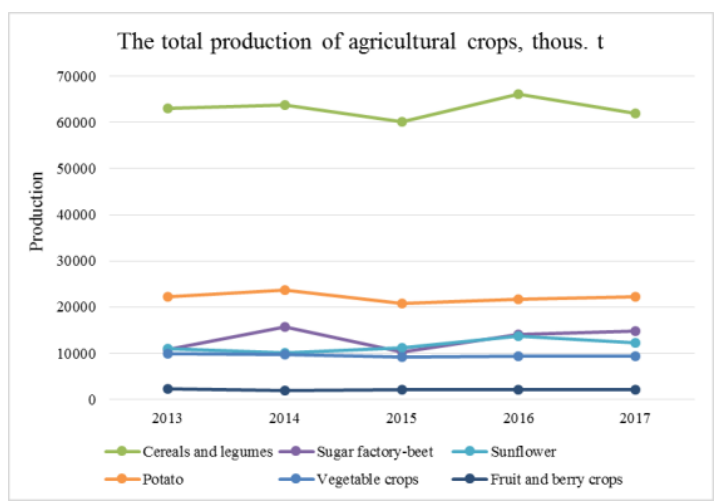

Fig. 2. Production of agricultural crops in Ukraine, thousand ton (author's development using [15])

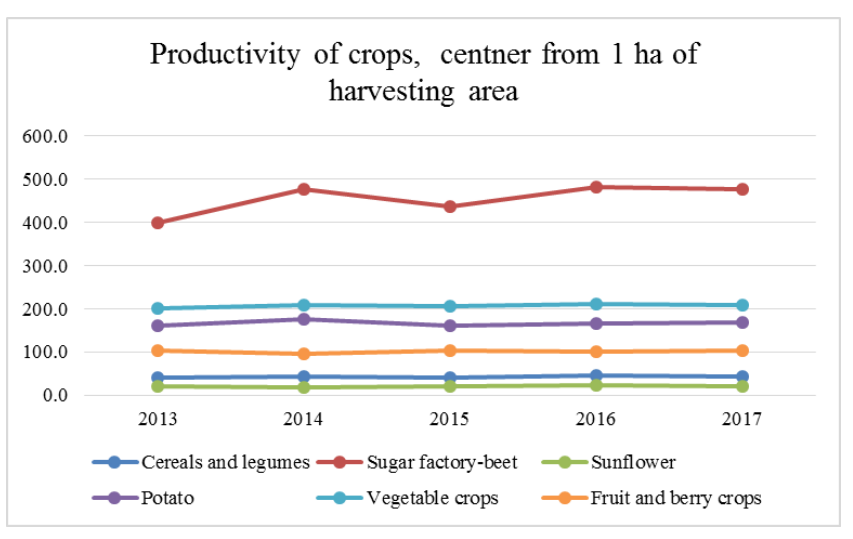

Fig. 3. Productivity of agricultural crops of Ukraine, center from 1 hectare of harvesting area (author's development using [15])

In 2015, biomass accounts for $64 \%$ of municipal solid waste. According to the data of the energy balance of Ukraine for 2016 [15], published at the end of 2017 (the energy balance for 2017 will be published in December 2018), the share of energy production from biofuels and biowaste in the structure of gross energy production amounted to $5.26 \%$ (3348 thousand. tons of oil equivalent (hereinafter - toe)), which is $81 \%$ of the total volume of renewable energy sources (hereinafter - RES).

The national action plan for renewable energy until 2020 (hereinafter - the NEAP) [12] provides for the achievement of $11 \%$ of renewable energy in gross final energy consumption in 2020. This percentage corresponds to the implementation of Ukraine's requirements to the Energy Community.

In parallel with the NEAP, Ukraine has an Energy Strategy for the period up to 2030 [10], the indicators of which contradict the NEAP.

In 2017, 3.5 billion cubic meters (hereinafter $-\mathrm{m} 3$ ) of gas substituted by bioenergy. The goal by 2020 is to replace 7.3 billion $\mathrm{m} 3$ of gas with biomass. The energy potential of Ukraine is estimated at 60 million tons of agricultural waste for bioenergy, with 20 million tons is enough to cover $25 \%$ of energy needs. The potential of Ukrainian bioenergy is estimated at 20 billion $\mathrm{m} 3$ of gas per year, which will export almost half, so Ukraine buys about 10 billion $\mathrm{m} 3$.

Dynamics of energy production from biofuels and waste of Ukraine and some countries in Europe and Asia, which is reflected in Figure 4, showed that Germany and France are the undisputed leaders among European countries.

This is due to the effective mechanism to support the development of bioenergy:

1) installation of "over-market" prices of traditional energy resources (natural gas, coal, petroleum products), which is achieved due to additional taxes;

2) the presence of inflated ("green") tariffs for electricity produced from renewable energy sources;

3) state support of programs with ambitious goals for RES development);

4) compensation of $20-40 \%$ to the end user of the total purchase cost of energy-saving equipment and equipment for the production of energy from renewable sources; 


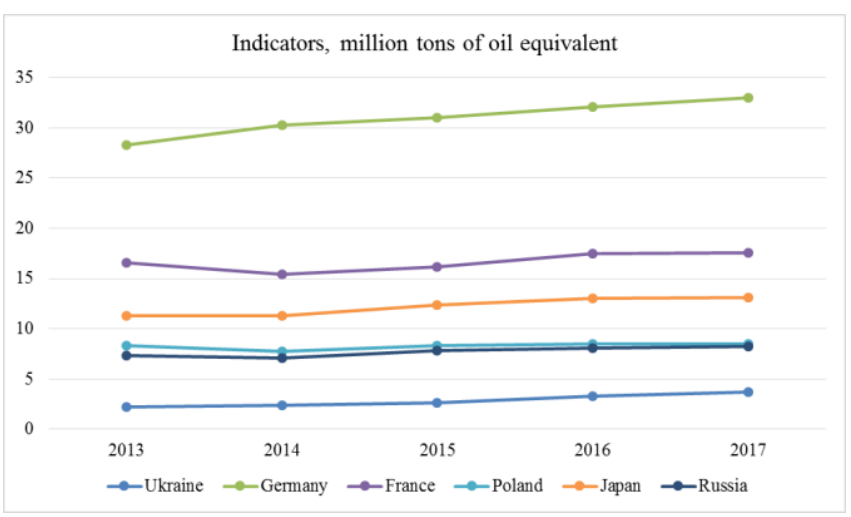

Fig. 4. Comparison of the dynamics of biofuel production and waste of some countries in Europe and Asia (developed by the authors using [5], [6]; [7])

Bioenergy production in the US and China is approximately at the same level without significant changes in the growth over the years (2013-2017). The average production in USA is 104 mega toe, China - an increase of 113.6 million toe.

The people's Republic of China has developed a five-year plan (2016-2020) for the development of bioenergy, which provides for investments in its own bioenergy up to 196 million yuan, the annual use of biomass 58 million tons of coal equivalent (for comparison, in 2015 this value reaches 35 million tons of equivalent), thereby reducing the consumption of fossil coal.

A positive factor affecting the development of bioenergy is the presence of a "green" tariff for electricity and heat from biomass. According to the "green" tariff, the state guarantees payment of energy production at a special rate, which exceeds the market price of electricity and is paid in euros (electricity from biomass costs 4018.5 UAH. per megawatts per hour) Domestic manufacturer for each kilowatts per hour receives 12.39 eurocents. Thermal energy according to the "green" tariff is $90 \%$ of the tariff for thermal energy due to natural gas.

The increase in gas prices for the development of bioenergy is also a positive factor, as it makes bioenergy more attractive in comparison with natural gas (the average gas price in 2018 is the highest in the history of the country).

In Ukraine, projects are being developed and developed within the framework of the National project "Energy of nature", including "Energy of biomass", "Energy of biogas".

A negative factor of influence on the author's opinion is the subsidization of traditional energy sources, in particular natural gas, which makes the transition to bioenergy not attractive. In the practice of European countries there is a reverse trend, which subsidized renewable energy.

Over the past five years, there has been an increase in the amount of subsidies in the structure of the state budget of Ukraine, and only 2019 in the budget is planned to reduce the amount of subsidies to 55.1 billion UAH, which is 15.9 billion less than in 2018. The dynamic of subsidizing rate is shown in the Table 1 .

For 2019 and 2020 it is planned to Finance 10-15 projects of Ukraine from bioenergy at the expense of the European
Bank for Reconstruction and Development (hereinafter EBRD) in the amount of 70-80 million euros. It is proposed to invest in the development of logistics, the shortcomings of which constrain the development of bioenergy.

TABLE I. SUBSIDIZING THE CONSUMPTION OF NATURAL GAS AT THE EXPENSE OF THE STATE BUDGET (20132019)

(developed by the authors using [6])

\begin{tabular}{|l|l|c|l|}
\hline $\begin{array}{l}\text { Heating } \\
\text { season }\end{array}$ & $\begin{array}{l}\text { The gross } \\
\text { amount of } \\
\text { subsidies, } \\
\text { billion UAH }\end{array}$ & $\begin{array}{c}\text { Absolute } \\
\text { growth, } \\
\text { billion UAH }\end{array}$ & $\begin{array}{l}\text { Growth } \\
\text { rate }\end{array}$ \\
\hline $2013-2014$ & 3.0 & & +6.00 \\
\hline $2014-2015$ & 18.0 & 15.0 & +2.62 \\
\hline $2015-2016$ & 47.1 & 29.1 & +1.10 \\
\hline $2016-2017$ & 52.0 & 4.9 & +1.37 \\
\hline $2017-2018$ & 71.0 & 19.0 & -0.22 \\
\hline $2018-2019$ & 55.1 & -15.9 & \\
\hline
\end{tabular}

Given the reduction in the amount of subsidies in the state budget of Ukraine, international cooperation, it can be concluded that the bioenergy sector of Ukraine will develop in the future.

Let is try to forecast the development of the domestic bioenergy sector based on the mean square deviation.

The dynamics of bioenergy development and the predicted value on the trend are shown in Figure 5.

Production of bioenergy, million tonns of oil equivalent

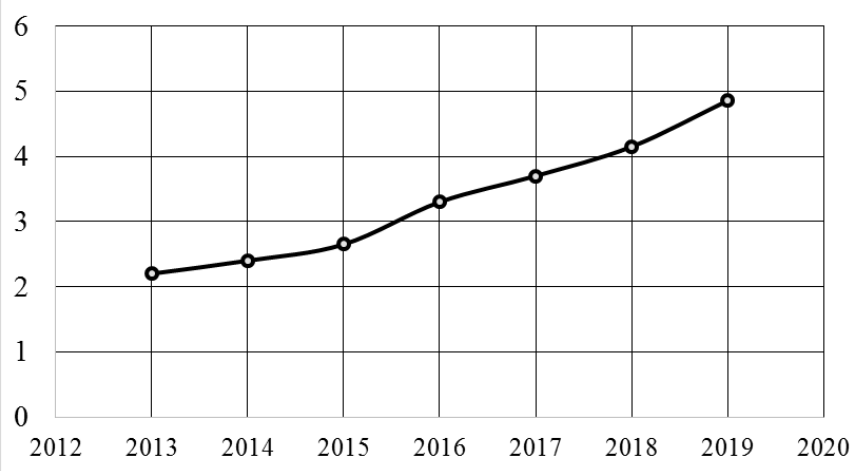

Fig. 5. Development of bioenergy in Ukraine and the value of the forecast (developed by the authors)

Globalization opens up enormous opportunities for investing in domestic business, in particular, bioenergy, which is necessary because experts believe, in particular, Heletukha H. H., Zhelyezna T. A. [3], that $11 \%$ of bioenergy in gross final consumption of Ukraine is an overvalued indicator, since modern production rates do not allow to achieve the planned goals. To achieve this indicator by domestic producers of bioenergy, taking into account the current pace of bioenergy development, maybe due to additional funding. Consider the economic benefits of investing in bioenergy in Ukraine.

Domestic agrarians will have an economic effect from the development of bioenergy through the use of ash after 
combustion of biomass as fertilizer. When reducing the volume of biomass residues in the field, the farmer reduces his own costs when managing them. At one ton, the farmer reduces costs by the amount of $262 \mathrm{UAH}$ per ton (the amount of the introduction of biological preparations - 42 $\mathrm{UAH}$ per ton and the addition of additional nitrogen fertilizers - $220 \mathrm{UAH}$ per ton). On one hectare there is an economy of 153 UAH per hectare (hereinafter - ha) (the amount of grinding and distribution of remnants by a combine - 90 UAH per ha and wrapping of straw (additional peeling) - 63 UAH per ha) [4, p. 13]

Consider the economic benefits of investing in a biomass boiler house with a capacity of 500 kilowatts and 3000 kilowatts, predicted in 2019, based on calculations [4, p. 31], and we will conduct an economic assessment of such an investment project.

Formula for calculating the total cost of planned production:

$$
\mathrm{TC}=\text { Qplan } * \mathrm{FC} * \mathrm{I}
$$

where $\mathrm{TC}-$ the total cost of planned production, UAH.

Qplan - the planned volume of production gigacalories (hereinafter - Gcal) (data of the planned volume of production is taken from [7, p. 31]).

FC - full cost, UAH per Gcal.

I - inflation rate (according to the state budget of Ukraine, the inflation rate is planned at 8\%).

The total cost of the planned volume of bioenergy production, using wood, wood pellets and straw pellets, respectively, will be according to the formula (1):

$$
\begin{aligned}
& \mathrm{TCw}=1152 * 757 * 1.08=941829.12(\mathrm{UAH}) \\
& \mathrm{TCwp}=1152 * 1073 * 1.08=1334983.68(\mathrm{UAH}) \\
& \mathrm{TCsp}=1152 * 985 * 1.08=1225497.6(\mathrm{UAH})
\end{aligned}
$$

Calculation of the total cost of the planned volume of heat production at the boiler capacity of $3000 \mathrm{~kW}$ on cod biomass:

$$
\mathrm{TCc}=6910 * 1045 * 1.08=7798626(\mathrm{UAH})
$$

The formula for calculating the projected profit from the implementation of the planned volume of bioenergy production by the considered types of boiler houses:

$$
\text { P2019 = Qp* Pforecast, }
$$

where Qp - projected profit from the implementation of the planned volume of bioenergy production by the considered types of boilers.

Pforecast - projected market cost of $1 \mathrm{Gcal}$ of energy from biomass "green" tariff.
Given the $23.5 \%$ rise in the cost of natural gas since November 2018, it can be concluded that 1 Gcal will cost $14 \%$ more compared to the base year 2018 .

If in 2018 the average price of 1 Gcal was about 1110 UAH., then in the projected year it will cost 1265.5 UAH. According to the "green" tariff, the cost of 1 Gcal per biomass is $10 \%$ less than that of natural gas. Volume $1 \mathrm{Gcal}$ of biomass will cost an average of about $1138.85 \mathrm{UAH}$. Substitute this value in the formula (2) to calculate the projected profit from the implementation of the planned volume of bioenergy production at the boiler capacity of 500 kilowatts on biomass from wood, wood pellets and straw pellets, respectively, and get $1311955 \mathrm{UAH}$ for each type of biomass.

As a result of the calculation of the projected profit from the implementation of the planned volume of bioenergy production at the boiler capacity of 3000 kilowatts on biomass from cod, we will receive a profit value of 7869 453.5 UAH.

The economic benefits of investing (as the difference between the gross cost of bioenergy and the projected profit from its implementation) in the production of thermal energy from biomass from wood, wood pellets and pellets from straw boilers with a capacity of 500 kilowatts and boilers with a capacity of $3000 \mathrm{~kW}$ for large chips will be respectively: $370125.88 \mathrm{UAH},-2328.68 \mathrm{UAH}, 106457.24$ $\mathrm{UAH}, 70827.5 \mathrm{UAH}$. The lack of profit at the projected rate of inflation is observed when investing in the production of bioenergy from wood pellets.

Economic evaluation of the investment project is the difference between the total cost of bioenergy and natural gas [4, p. 32].

The benefits of investing are obvious, apart from investing in the production of bioenergy from wood chips. In order for investment to become profitable, it is necessary to solve a number of problems. Such problems, in turn, constrain the development of bioenergy and the achievement of the NEAP TARGETS.

The analytical part of the work allowed the author to identify a number of measures that will further allow Ukraine to reach the world level of bioenergy development and achieve the goals of the NEAP:

1) creation of a mechanism for subsidizing buyers of bioenergy equipment;

2) providing a correct definition of "biomass" in the Law of Ukraine №5485-VI "On electricity" [1, p. 10], [12], [16];

3 ) reduction of the amount of state subsidies for domestic expenditures of natural gas;

4) increasing the coefficient of "green" tariff for energy from biogas;

5) development of the biofuel market, other than the bioenergy sector;

6) introduction of a "green" tariff for the production of bioelectricity from household waste. 


\section{CONCLUSION}

Globalization as a lever of stabilization can accelerate and simplify the process of bioenergy development. Thus, only in 2017, 1 billion euros were invested in RES. The process of globalization opens up enormous opportunities to invest in domestic business and improve the environmental condition of both Ukraine and the world as a whole, as indicated by the practice of foreign countries and their experience. Investing in bioenergy in Ukraine is advisable, as evidenced by the calculation of economic benefits, financing by international organizations, international cooperation. With additional funding and international support, it is possible to achieve the planned share of bioenergy in Ukraine's gross energy consumption.

\section{REFERENCES}

[1] Bioenergy Association of Ukraine, «Barriers to bioenergy development in Ukraine», Analytical note of BAU, no. 3, pp. 3-19, Jan. 2017.

[2] G. J. F. de Araujo, S. V. W. B de Oliveira, and M. M. B de Oliveira, "Economic Analysis of Internal Circulation Biodigesters and Vinasse Concentrators for the Generation of Electricity, Fertilizers, and Carbon Credits in Various Brazilian Economic Scenarios", BioEnergy Research, vol. 12, no. 45, pp. 1-23, September 2019. doi.org/10.1007/s12155-019-10030-9.

[3] H. Heletukha T. Zheleznaya, P. Kucheruk, E. Oliynyk, and A. Tryboi, «Bioenergy in Ukraine: current state and development prospects». Promislova teplotekhnika, vol. 37, no. 3, pp. 65-73, 2015.

[4] H. Heletukha, Yu. Matvyeyev, Ye. Oliynyk, and D. Kutsyy, “A Practical Guide to Using Biomass as Fuel in the Municipal Sector of Ukraine", United Nations Development Program, no. 37, 2017.

[5] International Energy Agency, « Final Report: Balance 2016», International Energy Agency, 2016. [Online]. Available: https://www.iea.org/Sankey/. Accessed on: August 20, 2019.

[6] International Energy Agency. [Online] Available:https://www.iea.org. Accessed on: August 20, 2019

[7] International Renewable Energy Agency. [Online]. Available: http://www.irena.org. Accessed on: August 20, 2019.
[8] J. R. Menucelli, E. Ph. Amorim, M. L. Freitas, M. Zanata, J. Cambuim, M. L. Teixeira de Moraes, F. M. Yamaji, F. Júnior, and E. L. Longui, "Potential of Hevea brasiliensis Clones, Eucalyptus pellita and Eucalyptus tereticornis Wood as Raw Materials for Bioenergy Based on Higher Heating Value", BioEnergy Research, vol. 12, no. 45, pp. 1-8, September 2019. doi.org/10.1007/s12155-019-10041-6.

[9] M. M. Kuz'mina, "Development of bioenergy in ukraine and in the world", Lawyer of Ukraine, vol. 4, no. 25, pp. 79-84, 2013.

[10] SF. Han, W. Jin, A. EF. Abomohra, R. Tu, X. Zhou, Zh. He, Ch. Chen, and GJ Xie, "Municipal Wastewater Enriched with Trace Metals for Enhanced Lipid Production of the Biodiesel-Promising Microalga Scenedesmus obliquus", BioEnergy Research, vol. 12, no. 45, pp. 1-23, September 2019. doi.org/10.1007/s12155-019-10042-5.

[11] State Statistics Service. [Online]. Available: http://ukrstat.gov.ua. Accessed on: August 20, 2019

[12] The Cabinet of Ministers of Ukraine. 8th Congress. (2014, Oct, 1). No. 902-th Decree "On the National Action Plan for Renewable Energy for the Period till 2020". [Online]. Available: http://zakon4.rada.gov.ua/laws/show/902-2014-\%D1\%80.

[13] The Cabinet of Ministers of Ukraine. 7th Congress. (2013, July, 24). №1071 Decree "Energy strategy of Ukraine for the period up to 2030". [Online]. Available: http://zakon5.rada.gov.ua/laws/show/n0002120-13/paran3\#n3.

[14] The Cabinet of Ministers of Ukraine. 8th Congress. (2015). The final version of the Energy Strategy of Ukraine for the period up to 2035. [Online]. Available: http://mpe.kmu.gov.ua/minugol/control/uk/doccatalog/list?currDir=50 358.

[15] The Ministry of Finance of Ukraine. 8th Congress. (2018). State and consolidated budget of Ukraine. [Online]. Available: https://index.minfin.com.ua/ua/finance/budget/.

[16] Verkhovna Rada of Ukraine. 2nd Congress. (1997, Oct., 16). No. 575/97-BP, as amended, Law of Ukraine "On Electricity". [Online]. Available: http://zakon2.rada.gov.ua/laws/show/575/97$\% \mathrm{D} 0 \% \mathrm{~B} 2 \% \mathrm{D} 1 \% 80$.

[17] W. D. Nordhaus, and J. E. Boyer, Warming the world: economic models of global warming. MA, USA: Massachusetts Institute of Technology, 2009. 